\title{
Heritability and Familiality of MMPI Personality Dimensions in the Korean Families with Schizophrenia
}

\author{
Hee Jeong Jeong ${ }^{1,2}$, Byung Dae Lee ${ }^{1,2,3} \bowtie$, Je Min Park ${ }^{1,2,3}$, Young Min Lee ${ }^{1,2,3}$, Eunsoo Moon ${ }^{1,2,3}$, \\ Soo Yeon Kim ${ }^{1,2}$, Kang Yoon Lee ${ }^{1,2}$, Hwagyu Suh ${ }^{1,2}$, and Young In Chung ${ }^{3}$ \\ ${ }^{1}$ Department of Psychiatry, Pusan National University Hospital, Busan, Republic of Korea \\ ${ }^{2}$ Medical Research Institute, Pusan National University Hospital, Busan, Republic of Korea \\ ${ }^{3}$ Department of Psychiatry, Pusan National University College of Medicine, Busan, Republic of Korea
}

\begin{abstract}
Objective Categorical syndrome such as schizophrenia could be the complex of many continuous mental structure phenotypes including several personality development/degeneration dimensions. This is the study to search heritability and familiality of MMPI personality dimensions in the Korean schizophrenic LD (Linkage Disequilibrium) families.

Methods We have recruited 204 probands (with schizophrenia) with their parents and siblings whenever possible. We have used MMPI questionnaires for measuring personality and symptomatic dimensions. Heritabilities of personality dimensions in total 543 family members were estimated using Sequential Oligogenic Linkage Analysis Routines (SOLAR). Personality dimensions in total family members were compared with those in 307 healthy unrelated controls for measuring the familialities using ANOVA analysis.

Results Seven of the 10 MMPI variables were significantly heritable and were included in the subsequent analyses. The three groups (control, unaffected 1st degree relative, case) were found to be significantly different with the expected order of average group scores for all heritable dimensions.

Conclusion Our results show that the aberrations in several personality dimensions could form the complexity of schizophrenic syndrome as a result of genetic-environment coactions or interactions in spite of some limitations (recruited family, phenotyping).
\end{abstract}

Psychiatry Investig 2018;15(12):1121-1129

Key Words Heritability, Familiality, MMPI, Dimension, Schizophrenia.

\section{INTRODUCTION}

Schizophrenia is a devastating mental illness that can lead to deterioration in the social and occupational function of affected individuals, ${ }^{1,2}$ with a major cost to society. ${ }^{3,4}$ A wide range of studies suggest a genetic component to the inheritance of this disorder. ${ }^{5}$ Although family, twin, and adoption studies have provided strong evidence that genetic variation plays a major role in the etiology of schizophrenia, susceptibility genes have proven difficult to definitively identify.

Many neuroscientific researchers are devoting their work to

Received: December 28, 2017 Revised: April 26, 2018

Accepted: October 21, 2018

$\triangle$ Correspondence: Byung Dae Lee, MD, PhD

Department of Psychiatry, Pusan National University Hospital, 179 Gudeok-ro, Seo-gu, Busan 49241, Republic of Korea

Tel: +82-51-240-7304, Fax: +82-51-248-3648, E-mail: bdlee@pusan.ac.kr

(c) This is an Open Access article distributed under the terms of the Creative Commons Attribution Non-Commercial License (https://creativecommons.org/licenses/by$\mathrm{nc} / 4.0$ ) which permits unrestricted non-commercial use, distribution, and reproduction in any medium, provided the original work is properly cited. elucidate its causes, especially in the field of basic genetics. However, the mystery concerning schizophrenia is consistent with the mystery surrounding the brain in general. Advances in elucidating the disorder are relatively smaller than the efforts of many researchers. Even a recent study performed in a large and heterogenous sample of European ancestry reported the discouraging finding that 14 genes previously consistently suggested to contribute to the susceptibility to schizophrenia may play a little role. ${ }^{6}$

However, much work at both the population and molecular levels remains before dismissing these genes and their connection to schizophrenia. Many suggest that alternatives should be searched in the phenotype. It is very clear that there are limitations in categorical phenotypes such as in a Diagnostic and Statistical Manual, 4th edition (DSM-IV)-based system. Many researchers are exploring comparable quantitative endophenotype alternatives to the classical qualitative phenotypes that represent schizophrenia.

Mode-of-inheritance studies have suggested that multiple 
genes are likely to be involved in the etiology of schizophrenia. If the effect of any single gene is generally modest for schizophrenia, we wonder whether we can identify clinical features that bind together more genetically homogeneous subtypes, facilitating susceptibility gene identification. Clinical subtyping has been an effective method in determining the etiology of other illnesses, such as Alzheimer's disease and breast cancer, in which families with early onset illness led researchers to the identification of disease genes. ${ }^{7,8}$

Several clinical features have been shown to increase the evidence of genetic linkage to chromosomal regions or association with gene variants. Comorbid panic disorder ${ }^{9}$ and bipolar II disorder ${ }^{10}$ appear to enhance linkage to distinct regions on chromosome 18q. In two datasets, psychotic features showed linkage to chromosome $13 \mathrm{q},{ }^{11,12}$ and early age at onset showed linkage to chromosome $21 \mathrm{q} 22$ in two cohorts. It has been reported that mania at onset enhances linkage to chromosome 16p and linkage to chromosome 2 was shown to be associated with attempted suicide in bipolar disorder. ${ }^{13}$ Psychotic features, mood-incongruent psychotic features, and persecutory delusions in bipolar disorder have strengthened evidence suggesting that there is a genetic association with DTNBP1 (dysbindin), NRG1 (neuregulin), and DAOA (G72), respectively. ${ }^{14}$ These early successes suggest that clinical phenomenology can help define more genetically homogenous forms of schizophrenia.

The choice of features studied in schizophrenia genetics has been guided largely by clinical experience. Features that show familial aggregation may be particularly promising, ${ }^{15}$ and most of the features, as mentioned previously, that enhance linkage or association signals are indeed familial. However, only a minority of the myriad clinical features in schizophrenia have been studied.

One possible mechanism for this phenomenon could be genetic aberrations in mental dimensions as sub(endo)phenotypes. Categorical syndromes such as schizophrenia could be a complex of many continuous phenotypes of mental structures, including several personality development/degeneration dimensions. Quantitative endophenotypes are needed to better understand the pathogenesis of schizophrenia. This concept was reflected in the recent publication of DSM- 5 and its definition of a schizophrenia spectrum and other psychotic disorders.

Many models suggest that personality dimensions are heritable and influence the genetic loading of schizophrenia. Personality traits are genetically influenced and the heritability of personality ranges from $30 \%$ to $60 \%$. Personality has a high familial tendency in the general population and in various psychiatric disorders including major depression, alcohol dependence, and bulimia. Besides neuropsychological or neurobiological characteristics, the biogenetic components of personality may also be considered an endophenotype of schizophrenia if they can be found both in schizophrenic probands and their first-degree relatives.

In DSM-IV, the diagnostic axis system remained. Axis-II personality disorders underlie axis-I symptomatic diagnosis, although personality disorder itself is regarded as a diagnostic entity. Personality is compared to defense in response to environmental stress. Psychiatric symptoms are interpreted as the result of altered defenses after exposure to environmental stress. Therefore, personality could be in line with psychiatric symptoms that result from a reaction to stressful events.

Many studies investigating the application of the Minnesota Multiphasic Personality Inventory (MMPI) in schizophrenia have been performed. They have included research concerning diagnostic issues in schizophrenia, methodological considerations in MMPI-based research of schizophrenia, and MMPI-based research of schizophrenia itself. Future research and clinical applications of these research findings are needed. The relationship between personality and schizophrenia is suggested. Personality can be categorized into three clusters, A, B, and C. Three clusters, though overlapping, are usually continuous with symptomatic dimensions. Psychosis, including schizophrenia, is commonly associated with cluster A personality.

Whether the precursors for psychopathology can be found in the personality dimensions of the general population has been determined. Schizophrenic symptoms could be understood to be continuous with schizotypal personality characteristics relative to controls based on the MMPI. These results suggest the usefulness of the MMPI subscales for the detection of subjects with the SPD trait. Furthermore, the SPD trait would be the genetic core for examining the transmissibility and familiality of schizophrenia. ${ }^{16-29}$

The MMPI results do not agree with a dimensional approach over a categorical approach. However, statistical validity could be improved with evaluating quantitative variables and their relationship with qualitative variables. Moreover, phenomenological accuracy would be heightened with a dimensional personality approach than could be accomplished by categorical diagnostic systems alone. This study aimed to investigate the heritability and familiality of MMPI personality dimensions in Korean families with schizophrenia.

\section{METHODS}

We recruited 204 probands with schizophrenia and their parents and siblings whenever possible. For the best estimation of diagnoses, we used medical records and a Korean version of the Diagnostic Interview for Genetic Studies (DIGS) 
Table 1. Demographic characteristics of the pedigree members, probands with schizophrenia, unaffected first-degree relatives, and control subjects as recruitment

\begin{tabular}{|c|c|c|c|c|c|}
\hline \multirow[b]{2}{*}{ Pedigree members } & \multirow{2}{*}{$\begin{array}{c}\text { Number of subjects } \\
543\end{array}$} & \multicolumn{2}{|c|}{ Age mean (SD/SEM) } & \multicolumn{2}{|c|}{ Sex male, N (\%)/female, N (\%) } \\
\hline & & & & & \\
\hline Probands with schizophrenia & 204 & $44.3(15.8 / 0.7)$ & $35.0(11.8 / 0.8)$ & $255(47.0) / 288(53.0)$ & $102(50.0) / 102(50.0)$ \\
\hline Unaffected first-degree relatives & 339 & & $50.3(15.2 / 0.9)$ & & $153(45.1) / 186(54.9)$ \\
\hline Control members & 307 & & & & \\
\hline Unrelated subjects & 307 & $28.7(2.9 / 0.2)$ & $28.7(2.9 / 0.2)$ & $159(51.8) / 148(48.2)$ & $159(51.8) / 148(48.2)$ \\
\hline Statistics & NA & $\mathrm{t}=14.6$ & $\mathrm{~F}=242.1$ & $\chi^{2}=1.8$ & $\chi^{2}=3.0$ \\
\hline $\mathrm{p}$ value & & $<0.001$ & $<0.001$ & 0.2 & 0.2 \\
\hline
\end{tabular}

SD: standard deviation, SEM: standard error of the mean, NA: not applicable

and Family Interview for Genetic Studies (FIGS). We used the MMPI questionnaire to measure the personality dimensions (Table 1).

The MMPI is the most widely used self-report objective personality assessment. It was originally developed for diagnostic classification in psychiatry, but is now widely used for psychopathologic classification and describing personality characteristics and behavioral characteristics in healthy control subjects. The MMPI is the most widely used and researched objective measure of psychopathology in professional psychology. It consists of the three validity subscales (Lie, L; Infrequency, F; Defensiveness, K) and 10 clinical subscales (Hypochondriasis, Hs; Depression, D; Hysteria, Hy; Psychopathic Deviance, Pd; Masculinity-Femininity, Mf; Paranoia, Pa; Psychasthenia, Pt; Schizophrenia, Sc; Mania, Ma; and Social Introversion, $\mathrm{Si}$ ). In our study, we used the Korean version that consists of 556 statements, standardized by Kim et al..$^{30}$

Schizotypal personality disorder patients (SPD) showed significantly elevated Pt and Si scales relative to schizophrenic patients. Schizophrenia and SPD groups generally produced two-point codetypes of 6-8/8-6, 2-6/6-2, 7-8/8-7, and $7-8 / 8-7,2-7 / 7-2,6-8 / 8-6$. College students had no codetype with a T-value of $\geq 70$, although the frequency of codetypes of spike 5 , spike 0 , and 2-7/7-2 was relatively higher in the student group than in the general population. Discriminant function analysis of the MMPI profiles revealed significant variance among the three groups. The overall rate of correct classification of the subjects into schizophrenia, SPD, or college students was significant. The first coefficient, mainly defined by a negative weight on the Sc scale, best distinguished patients with either schizophrenia or SPD from the students. The second coefficient, defined by negative weights on the Sc and Si scales, and positive weights on the F and Ma scales identified patients with schizophrenia and SPD patients. The Harris-Lingoes subscales, which are supposed to provide the profile patterns characteristic of schizotypy, discriminated the three groups well. ${ }^{16-29}$

\section{Sample collection}

All subjects were recruited and gave informed consent in accordance with the principles of the Declaration of Helsinki and with approval from the Institutional Review Boards of the Pusan National University Hospital (IRB No. 0908-003-001) (Figure 1). Probands were recruited independently from the Pusan National University Hospital. All probands had disease onset by age 40 , a history of at least one psychiatric hospitalization, discharge diagnosis of schizophrenia, and Korean surnames. Parents and first-degree relatives of probands were also recruited where possible to permit determination of the genetic phase and allow for family-based linkage disequilibrium analyses. If additional relatives with psychotic disorders were detected, efforts were made to recruit these relatives as well. Each subject was interviewed by a trained Korean psychiatrist, who was blinded to the previous history of the subject, using the Korean version of DIGS. ${ }^{31}$ Medical records (inpatient and outpatient) were also abstracted. An interview with a close relative, using a Korean version of the FIGS, was also completed for each subject. ${ }^{32}$ In total, 204 probands and their available family members were analyzed in the current study. All affected subjects (i.e., those given formal psychiatric diagnoses for the present study) within each family were diagnosed using a best estimate diagnostic process, as described by Walss-Bass et al..$^{33}$ The process arrives at a lifetime consensus diagnosis or diagnosis using the DSM-IV. The number of subjects and families analyzed in this study were as follows: 543 subjects from 204 families. Of those, 204 probands had an axis I disorder by consensus DSM-IV diagnosis of schizophrenia. In addition, 339 other family members, including first degree relatives who had no axis I disorder diagnosis, were selected.

A total of 204 subjects had a history of psychosis, operationalized in this study as the presence of at least one of the following at some point during their lifetime: hallucinations, delusions, grossly disorganized thought processes, or grossly disorganized behavior. This definition of psychosis corresponds to four of the five symptoms and signs listed under Criteria A of the DSM-IV definition of schizophrenia. We did 


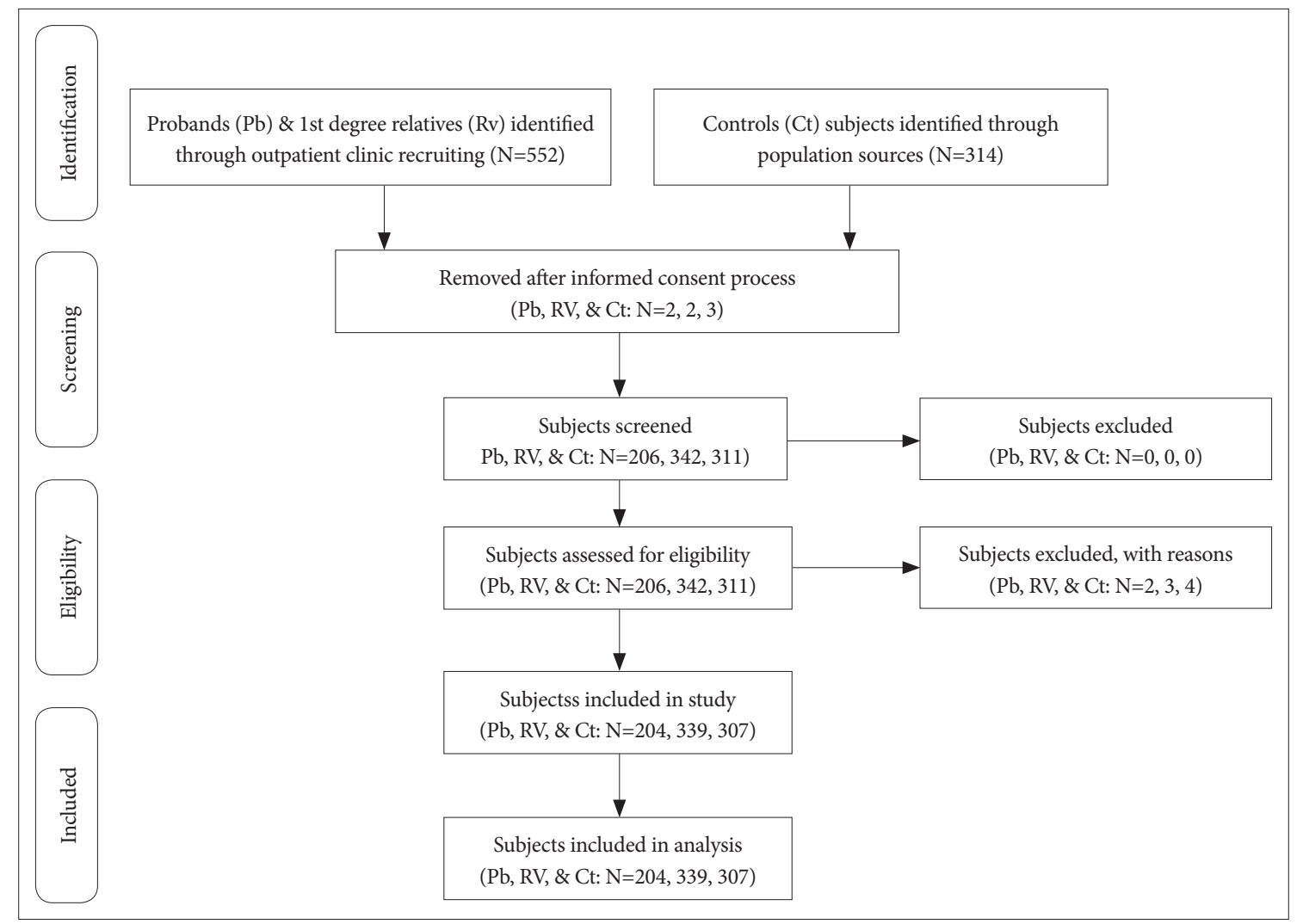

Figure 1. Flowchart for recruitment of the pedigree members, probands with schizophrenia, unaffected first-degree relatives, and control subjects.

not consider a history of "negative symptoms" (abulia, alogia, avolition), also listed under Criteria A of the DSM-IV definition of schizophrenia, as sufficient for a diagnosis of psychosis. For each subject, the best estimators also diagnosed whether manic syndromes or episodes had been present during the course of the disorder. The distinction between schizophrenia and schizoaffective disorder followed the criteria of the DSM-IV, as operationalized in Walss-Bass et al. ${ }^{33}$

Our study included 307 Korean control subjects who were psychiatrically healthy and belonged to the age groups specified in the sample. Subjects with potentially biasing conditions were excluded from the study. Subjects were also excluded if they had been receiving corticoid, estrogen, androgen, or T3 (triiodothyronine)-T4 (thyroxine) therapy, or diphenylhydantoin, vitamin $\mathrm{D}$, bisphosphonate, calcitonin, fluoride, thiazide diuretics, or barbiturates for more than 6 months, as all these drugs may have biasing effects. Because it was impossible to obtain a population-based register for technical and legal reasons, control subjects meeting the inclusion/exclusion criteria were identified from among volunteers (students and hospital workers) at the hospital.

\section{Statistical analysis}

The heritability of personality dimensions in a total of 543 family members was estimated using Sequential Oligogenic Linkage Analysis Routines (SOLAR). ${ }^{34}$ Personality dimensions in the family members were compared with those in the 307 healthy unrelated controls for measuring the familiality using an analysis of variance (ANOVA) performed using SPSS, version 11.5 (SPSS Inc., Chicago, IL, USA). Statistical corrections for age covariates were performed because there were significant differences between groups. Genetic/environmental correlations with symptomatic dimensions for significant personality dimensions aggregated in families were also investigated using SOLAR (Southwest Foundation for Biomedical Research, San Antonio, TX, USA). The required significance level was 5\%.

The heritability of personality dimensions was estimated in a total of 543 family members using SOLAR. ${ }^{34}$ SOLAR is an extensive, flexible software package for genetic variance component analysis, including linkage analysis, quantitative genetic analysis, single-nucleotide polymorphisms (SNP) association analysis (QTN, QTLD, and MGA), and covariate screening. Operations are included for the calculation of marker-specific or multipoint identity-by-descent (IBD) matrices in pedigrees of arbitrary size and complexity, and for linkage analysis of multiple quantitative traits and/or discrete traits that may involve multiple loci (oligogenic analysis), dominance effects, household effects, and interactions. Heritability represents 
the portion of the phenotypic variance accounted for by the total additive genetic variance. Genetic variance is the portion of phenotypic variance due to pedigree relationships rather than environmental factors or error. Indices with stronger covariance between genetically more similar individuals rather than between genetically less similar individuals have higher heritability. Within the SOLAR program, this is assessed by contrasting the observed covariance matrices for a trait with the covariance matrix predicted by kinship. MMPI variables without significant heritability, corrected for multiple comparison at a $5 \%$ false discovery rate (FDR), were not excluded in subsequent analyses considering the opinion that MMPI codes more specific to schizophrenia do not need to have high heritability and they will be influenced by both genetic and environmental factors. Personality dimensions in all the family members were compared with those in 307 healthy unrelated controls to analyze heritability using an ANOVA. Scheffe's post-hoc test, widely used as a contrast, was applied instead of Tukey-Kramer's or Student-Neumann-Keuls's tests. Genetic/environmental correlations with symptomatic dimensions for significant personality dimensions aggregated in families were also investigated using SOLAR. Although the difference in the MMPI measures between unaffected first-degree relatives and controls that rule out effects secondary to disease in the affected individuals are indicative of genetic vulnerability, they could also be due to environmental factors shared by individuals with schizophrenia and their unaffected relatives. To determine whether MMPI personality scores and liability for schizophrenia have common genetic or environmental influences, mixed discrete/continuous trait bivariate analyses were conducted. These analyses decompose phenotypic correlations into genetic (g) and environmental (e) correlations between the two traits. If the genetic correlation is significantly different from 0 , then the traits are considered to be influenced by the same genetic factors. If the environmental correlation is significantly different from 0 , then the traits are considered to be influenced by the same environmental factors. The significance (5\% FDR) of these correlations was tested by comparing the natural log (ln) likelihood for two restricted models (with g or e constrained to equal 0.0) against the ln likelihood for the model in which these parameters were estimated. Finally, we performed multivariate analyses on those MMPI traits that were genetically correlated with schizophrenia to determine whether these traits represent independent risk factors. All statistical analyses were performed using SPSS, version 11.5. The required significance level was set at $5 \%$.

\section{RESULTS}

\section{Heritability}

Seven of the 10 MMPI variables were significantly heritable and were included in the subsequent analyses. Heritability was the highest for hysteria $(0.37, \mathrm{p}=0.0006)$ and lowest for schizophrenia $(0.23, \mathrm{p}=0.02)$. Three MMPI variables (masculinity-femininity, paranoia, and psychasthenia) were not significantly heritable. We did not exclude them from subsequent analyses considering the opinion that MMPI codes more specific to schizophrenia do not need to have high heritability and are influenced by both genetic and environmental factors (Table 2).

\section{Familial aggregation}

The control, unaffected 1st degree relative, and case groups were significantly different and with the expected order of average group scores for all heritable dimensions. Seven heritable dimensions (high hypochondriasis, high depression, high hysteria, high psychopathic deviance, high schizophrenia, high hypomania, and high social introversion) could differentiate the case group from the 1st degree relatives and control group

Table 2. Heritability ( $\mathrm{H} 2 \mathrm{r})$ of MMPI personality measures

\begin{tabular}{lccccc}
\hline \multicolumn{1}{c}{ Personality dimensions } & H2r & H2r (SEM) & p value & Significant covariates & $\begin{array}{c}\text { Proportion of H2r due } \\
\text { to significant covariates }\end{array}$ \\
\hline Hypochondriasis & 0.30 & 0.11 & 0.00 & AGE*sex & 0.01 \\
Depression & 0.30 & 0.12 & 0.00 & AGE, AGE*sex & 0.01 \\
Hysteria & 0.37 & 0.11 & 0.00 & AGE*sex & 0.01 \\
Psychopathic deviance & 0.34 & 0.14 & 0.01 & AGE, AGE ${ }^{*}$ & 0.02 \\
Masculinity-Feminity & 0.00 & NA & 0.50 & AGE*sex & 0.00 \\
Paranoia & 0.12 & 0.13 & 0.17 & AGE & 0.04 \\
Psychasthenia & 0.11 & 0.12 & 0.18 & AGE & 0.02 \\
Schizophrenia & 0.23 & 0.12 & 0.02 & AGE & 0.03 \\
Hypomania & 0.26 & 0.12 & 0.01 & AGE ${ }^{2}$ AGE ${ }^{2 *}$ sex & 0.02 \\
Social introversion & 0.36 & 0.12 & 0.00 & AGE, sex & 0.05 \\
\hline
\end{tabular}

MMPI: Minnesota Multiphasic Personality Inventory, SEM: standard error of the mean, NA: not applicable 
Table 3. Familial aggregation of personality measures

\begin{tabular}{|c|c|c|c|c|c|}
\hline Personality dimensions & Control & Unaffected 1 st degree relative & Case & $\mathrm{p}$ value & $\mathrm{p}$ value adjusted for age \\
\hline Hypochondriasis & $49.9 \pm 7.9$ & $53.6 \pm 10.8^{*}$ & $57.2 \pm 11.6^{* \dagger}$ & $<0.001$ & $<0.001$ \\
\hline Depression & $46.4 \pm 8.9$ & $53.3 \pm 10.3^{*}$ & $59.3 \pm 12.6^{* \dagger}$ & $<0.001$ & $<0.001$ \\
\hline Hysteria & $47.4 \pm 8.8$ & $53.6 \pm 11.3^{*}$ & $56.8 \pm 11.9^{* \dagger}$ & $<0.001$ & $<0.001$ \\
\hline Psychopathic deviance & $50.1 \pm 9.1$ & $54.0 \pm 10.1^{*}$ & $56.7 \pm 11.4^{* \dagger}$ & $<0.001$ & $<0.001$ \\
\hline Masculinity-feminity & $48.4 \pm 10.2$ & $49.5 \pm 9.6$ & $51.7 \pm 9.6^{* \dagger}$ & 0.002 & 0.001 \\
\hline Paranoia & $43.7 \pm 7.9$ & $47.1 \pm 10.3^{*}$ & $54.9 \pm 12.4^{* \dagger}$ & $<0.001$ & $<0.001$ \\
\hline Psychasthenia & $45.1 \pm 7.8$ & $48.6 \pm 9.9^{*}$ & $56.5 \pm 12.4^{* \dagger}$ & $<0.001$ & $<0.001$ \\
\hline Schizophrenia & $42.4 \pm 7.6$ & $46.6 \pm 9.5^{*}$ & $56.3 \pm 13.4^{* \dagger}$ & $<0.001$ & $<0.001$ \\
\hline Hypomania & $37.7 \pm 9.5$ & $42.0 \pm 9.3^{*}$ & $44.6 \pm 11.4^{* \dagger}$ & $<0.001$ & $<0.001$ \\
\hline Social introversion & $45.4 \pm 9.8$ & $47.3 \pm 10.1^{*}$ & $53.9 \pm 12.2^{* \dagger}$ & $<0.001$ & $<0.001$ \\
\hline
\end{tabular}

Values are presented as mean \pm standard deviation (standard error of the mean). ${ }^{*} \mathrm{p}<0.05$ compared to controls by Scheffe test, ${ }^{\dagger} \mathrm{p}<0.05$ compared to 1st degree relatives by Scheffe test

Table 4. Bivariate analysis between disease status \& personality measures

\begin{tabular}{|c|c|c|c|c|}
\hline \multirow{3}{*}{ Personality dimensions } & \multicolumn{4}{|c|}{ Schizophrenic phenotype } \\
\hline & \multicolumn{2}{|c|}{ Genetic correlation } & \multicolumn{2}{|c|}{ Environmental correlation } \\
\hline & $\rho g(\mathrm{SE})$ & $\mathrm{p}$ value & $\rho e(S E)$ & $\mathrm{p}$ value \\
\hline Hypochondriasis & $0.02(1.00)$ & 1 & $0.18(0.22)$ & 0.05 \\
\hline Depression & $-1.00(\mathrm{NC})$ & 0.91 & $0.29(0.06)$ & $5.71 \mathrm{e}^{-07}$ \\
\hline Hysteria & $0.04(1.00)$ & 1.00 & $0.15(0.06)$ & 0.01 \\
\hline Psychopathic deviance & $-1.00(\mathrm{NC})$ & 0.85 & $0.16(0.10)$ & 0.05 \\
\hline Masculinity-feminity & $0.01(\mathrm{NC})$ & 1 & $0.14(0.07)$ & 0.01 \\
\hline Paranoia & $-1.00(\mathrm{NC})$ & 0.81 & $0.37(0.06)$ & $7.81 \mathrm{e}^{-12}$ \\
\hline Psychasthenia & $-0.02(1.34)$ & 1 & $0.37(0.07)$ & $1.10 \mathrm{e}^{-12}$ \\
\hline Schizophrenia & $0.02(0.00)$ & 1 & $0.48(0.07)$ & $2.21 \mathrm{e}^{-17}$ \\
\hline Hypomania & $0.04(1.01)$ & 1 & $0.17(0.10)$ & 0.00 \\
\hline Social introversion & $0.17(2.79)$ & 1 & $0.35(0.06)$ & $1.41 \mathrm{e}^{-09}$ \\
\hline
\end{tabular}

Pg: genetic correlation coefficient, SEM: standard error of the mean, $\rho e$ environmental correlation coefficient, NC: not computable

qualitatively $(\mathrm{p}=<0.001)$ (Table 3$)$.

\section{Genetic/environmental correlation}

The genetic/environmental correlations with the schizophrenic phenotype are displayed in Table 4 . There were no genetic correlations with the schizophrenic phenotype for any MMPI personality dimensions. In contrast, environmental correlations were suggested for all dimensions $(\mathrm{p}<0.05)$ (Table 4).

\section{DISCUSSION}

Our results show that the aberrations in several personality dimensions could underlie the complexity of the schizophrenic syndrome as a result of genetic-environment coactions or interactions. Seven heritable endophenotypes (high hypochondriasis, high depression, high hysteria, high psychopathic deviance, high schizophrenia, high hypomania, and high social introversion) could qualitatively differentiate the patients from the 1st degree relatives and controls. These could mean that some MMPI types are heritable in schizophrenic pedigrees and form the familial psychotic characteristics. There were no genetic correlations with the schizophrenic phenotype for any MMPI personality dimensions. In contrast, environmental correlations were suggested for all dimensions. These results could be interpreted as personality traits not being influenced by the same factors and being a complex result of geneenvironment interactions. Gene-environment interactions are represented as the coactions of genetic variation and environmental factors.

Traditional MMPI interpretation has frequently relied on classifying profiles according to the two or three highest Tscores on the clinical scales, ${ }^{16}$ and several researchers have reported two-point code types that are frequently exhibited by patients with schizophrenia..$^{16,35-37}$ Moldin et al. ${ }^{38}$ evaluated the power of each MMPI indicator, including mainly schizo- 
phrenic (MS) code types, in the New York High-Risk Study and concluded that the indicators are useful in identifying a schizophrenic phenotype, regardless of severity, and in several stages of decompensation of remission. These code types for schizophrenia usually do not actually indicate schizophrenia per se, but are applied clinically as suggesting a possible underlying psychosis or distress. However, the studies cited above have suggested that the schizophrenia-related code types to some extent reflect the thought and experience characteristics of schizophrenia, although they are limited by the susceptibility to state-dependent influences. ${ }^{38}$

We agree that categorical phenotypes are still valid for genetic research focusing on finding the genetic origins of mental illnesses including schizophrenia. Simultaneously, the limitation of categorical phenotypes is undeniable and is proven through the failure thus far of finding candidate genes in schizophrenia genetic research. Personality endophenotypes could be an alternative method for overcoming the obstacles that genetic research faces. Our study can be the basis for endophenotype research in schizophrenia by suggesting that the some MMPI personality dimensions are heritable in Korean pedigrees with schizophrenia and they are aggregated in probands and 1st degree relatives relative to unrelated controls. ${ }^{39}$

Meehl ${ }^{40}$ in his genetic/interactional theory of schizophrenia, hypothesized that a neural integrative defect, which he termed schizotaxia (also known as the schizoid-taxon), is the inherited basis for schizophrenia. Certain social learning experiences then interact with this schizotaxic foundation to form a personality structure referred to as schizotypy. Under environmental stress, the schizotype is likely to decompensate into schizophrenia. Therefore, while Meehl believes all schizophrenics have a schizotaxic foundation, not all schizotaxic individuals manifest schizophrenic symptoms. There are some addressed issues concerning whether the MMPI can aid in the detection and understanding of schizotaxia and schizotypy.

The high-point code felt by many to be significantly associated with the schizotypal personality is a triad involving scales 2 (D), $7(\mathrm{Pt})$, and $8(\mathrm{Sc}) .^{41-44}$ Fine $^{45}$ reported that a group of college students possessing the $2-7-8$ triad exhibited characteristics similar to the behaviors of hospitalized schizophrenics. The presence of a cognitive/perceptual deficit has also been documented in individuals exhibiting the 2-7-8 triad. More specifically, research has revealed the presence of a deficit in the iconic storage of visual material, ${ }^{46}$ impaired shortterm memory and encoding, ${ }^{42,47}$ and disturbances in the ability to access information from long-term memory ${ }^{48}$ in subjects with the $2-7-8$ profile. This series of deficits, all involving aspects of memory, may lead to the development of delusions and other cognitive disturbances frequently encountered in schizophrenia. However, with the exception of the study of Koh, Kayton, and Berry, this research has been conducted on undergraduate psychology students. Therefore, one needs to be cautious in generalizing the results of these studies to patient populations since the correlations between MMPI scales (and most probably their relationship to other variables as well) can vary on the basis of the nature of subjects employed. ${ }^{49}$

MMPI is different from a diagnostic entity from the point of describing personality items that evaluate the degree of dimensions. Simply, the efforts to overcome the limitation of categorical phenotypes in the representative DSM diagnostic system are very much needed as a result of the failures in finding candidate genes using classical schizophrenic phenotypes in psychiatric genetic research. We used the MMPI questionnaire, a common personality psychometry tool to assess quantitative dimensional endophenotypes, as an alternative to categorical phenotypes with their many limitations. Compared to previous results (high-point code MMPI 2-7-8 and $2-7-8-0$ scales), our results partly replicate the high MMPI scales in probands and unaffected 1st degree relatives. However, this could be different from previous results suggesting the high-point code issues in schizophrenia. There are some opinions that MMPI codes more specific to schizophrenia do not need to have high heritability. Our results partly reflect this view, suggesting that there were no genetic correlations with the schizophrenic phenotype for any MMPI personality dimensions, but environmental correlations for all the dimensions.

This study is in line with the previous findings that some personality dimensions are heritable in families with schizophrenia and could be very promising endophenotypic markers for schizophrenia, although there are several limitations including recruited families and phenotyping. ${ }^{50-52}$ These will be the base of the important coefficients of the thus far mysterious equations describing schizophrenia. Nonetheless, most aspects of the positional genetic variations and environmental factors as loaded variables of the equations underlying that syndrome remain doubtful.

Most importantly, future genome-wide linkage and association studies with much more complete pedigrees are expected. At that time, FBAT analyses in families with subtyped schizophrenic probands according to personality, working memory, and cognition, in addition to previously described quantitative traits, will facilitate fine mapping analyses to identify candidate genes of schizophrenia, which is a huge challenge faced by contemporary psychiatrists.

\section{REFERENCES}

1. McGuffin P, Asherson P, Owen M, Farmer A. The strength of the genetic effect. Is there room for an environmental influence in the aetiology of schizophrenia? Br J Psychiatry 1994;164:593-599. 
2. Bachmann RF, Schloesser RJ, Gould TD, Manji HK. Mood stabilizers target cellular plasticity and resilience cascades: implications for the development of novel therapeutics. Mol Neurobiol 2005;32:173-202.

3. Bartels SJ, Clark RE, Peacock WJ, Dums AR, Pratt SI. Medicare and medicaid costs for schizophrenia patients by age cohort compared with costsfor depression, dementia, and medically ill patients. Am J Geriatr Psychiatry 2003;11:648-657.

4. Bauer M, Unutzer J, Pincus HA, Lawson WB; NIMH Affective Disorders Workgroup. Bipolar disorder. Ment Health Serv Res 2002;4:225229.

5. Shih RA, Belmonte PL, Zandi PP. A review of the evidence from family, twin and adoption studies for a genetic contribution to adult psychiatric disorders. Int Rev Psychiatry 2004;16:260-283.

6. Sanders AR, Duan J, Levinson DF, Shi J, He D, Hou C, et al. No significant association of 14 candidate genes with schizophrenia in a large European ancestry sample: implications for psychiatric genetics. Am J Psychiatry 2008;165:497-506.

7. Goate A, Chartier-Harlin MC, Mullan M, Brown J, Crawford F, Fidani $\mathrm{L}$, et al. Segregation of a missense mutation in the amyloid precursor protein gene with familial Alzheimer's disease. Nature 1991;349:704706.

8. Miki Y, Swensen J, Shattuck-Eidens D, Futreal PA, Harshman K, Tavtigian $\mathrm{S}$, et al. A strong candidate for the breast and ovarian cancer susceptibility gene BRCA1. Science 1994;266:66-71.

9. MacKinnon DF, Xu J, McMahon FJ, Simpson SG, Stine OC, McInnis MG, et al. Bipolar disorder and panic disorder in families: an analysis of chromosome 18 data. Am J Psychiatry 1998;155:829-831.

10. McMahon FJ, Simpson SG, McInnis MG, Badner JA, MacKinnon DF, DePaulo JR. Linkage of bipolar disorder to chromosome $18 \mathrm{q}$ and the validity of bipolar II disorder. Arch Gen Psychiatry 2001;58;1025-1031

11. Potash JB, Zandi PP, Willour VL, Lan TH, Huo Y, Avramopoulos D, et al. Suggestive linkage to chromosomal regions $13 \mathrm{q} 31$ and $22 \mathrm{q} 12$ in families with psychotic bipolar disorder. Am J Psychiatry 2003;160:680-686.

12. Park N, Juo SH, Cheng R, Liu J, Loth JE, Lilliston B, et al. Linkage analysis of psychosis in bipolar pedigrees suggests novel putative loci for bipolar disorder and shared susceptibility with schizophrenia. Mol Psychiatry 2004;9:1091-1099.

13. Willour VL, Zandi PP, Badner JA, Steele J, Miao K, Lopez V, et al. Attempted suicide in bipolar disorder pedigrees: evidence for linkage to 2p12. Biol Psychiatry 2007;61:725-727.

14. Raybould R, Green EK, MacGregor S, Gordon-Smith K, Heron J, Hyde $\mathrm{S}$, et al. Bipolar disorder and polymorphisms in the dysbindin gene (DTNBP1). Biol Psychiatry 2005;57:696-701.

15. Schulze TG, McMahon FJ. Defining the phenotype in human genetic studies: forward genetics and reverse phenotyping. Hum Hered 2004; 58:131-138.

16. Walters GD. The MMPI and schizophrenia: review. Schizophr Bull 1983;9:226-246.

17. Carter JW, Parnas J, Cannon TD, Schulsinger F, Mednick SA. MMPI variables predictive of schizophrenia in the Copenhagen high-risk project: a 25-year follow-up. Acta Psychiatr Scand 1999;99:432-440.

18. Claridge G, Beech T. Fully and Quasi-Dimensional Constructions of Schizotypy. In: Raine A, Lencz T, Mednick SA, Editors. Schizotypal Personality. Cambridge University Press: New York, 1995, p.192-216.

19. Matsui M, Gur RC, Turetsky BI, Yan M, Gur RE. The relation between tendency for psychopathology and reduced frontal brain volume in healthy people. Neuropsychiatry Neuropsychol Behav Neurol 2000;13: 155-162.

20. Haier RJ, Murphy DL, Buchsbaum MS. Paranoia and platelet MAO in normals and nonschizophrenic psychiatric groups. Am J Psychiatry 1979; 136:308-310.

21. Haier RJ, Buchsbaum MS, Murphy DL, Gottesman II, Coursey RD. Psychiatric vulnerability, monoamine oxidase, and the average evoked potential. Arch Gen Psychiatry 1980;37:340-345.

22. Ogura C, Hirano K, Nageishi Y, Takeshita S, Fukao K, Hokama H, et al.
Deviate P200 and P300 in non-patient college students with high scores on the schizophrenia scale of the Minnesota Multiphasic Personality Inventory (MMPI). Int J Psychophysiol 1994;16:89-97.

23. Haier RJ, Rieder RO, Khouri PJ, Buchsbaum MS. Extreme MMPI scores and the Research Diagnostic Criteria. Screening college men for psychopathology. Arch Gen Psychiatry 1979;36:528-534.

24. Lenzenweger MF. Confirming schizotypic personality configurations in hypothetically psychosis-prone university students. Psychiatry Res 1991;37:81-96.

25. Merritt RD, Balogh DW, DeVinney SE. Use of the MMPI to assess the construct validity of the revised social anhedonia scale as an index of schizotypy. J Pers Assess 1993;60:227-238.

26. Moldin SO, Gottesman II, Erlenmeyer-Kimling L. Psychometric validation of psychiatric diagnoses in the New York High-Risk study. Psychiatry Res 1987;22:159-177.

27. Chapman LJ, Chapman JP, Raulin ML. Body-image aberration in schizophrenia. J Abnorm Psychol 1978;87:399-407.

28. Chapman LJ, Chapman JP, Raulin ML. Scales for physical and social anhedonia. J Abnorm Psychol 1976;85:374-382.

29. Greene RL. The MMPI-2/MMPI. An Interpretive Manual. Boston: Allyn \& Bacon; 1991.

30. Kim YH, Kim JH, Kim JS, Noh MR, Shin DG, Yeum TH, et al. The Main Principles for Minnesota Multiphasic Personality Inventory (MMPI). Seoul: Korea Guidance; 1989.

31. Nurnberger JI Jr, Blehar MC, Kaufmann CA, York-Cooler C, Simpson SG, Harkavy-Friedman J, et al. Diagnostic interview for genetic studies. Rationale, unique features, and training. NIMH Genetics Initiative. Arch Gen Psychiatry 1994;51:849-859; discussion 863-864.

32. Maxwell ME. Family Interview for Genetic Studies (FIGS): Manual For FIGS. (Clinical Neurogenetics Branch, Intramural Research Program). Bethesda, MD: National Institute of Mental Health; 1992

33. Walss-Bass C, Escamilla MA, Raventos H, Montero AP, Armas R, Dassori A, et al. Evidence of genetic overlap of schizophrenia and bipolar disorder: linkage disequilibrium analysis of chromosome 18 in the Costa Rican population. Am J Med Genet B Neuropsychiatri Genet 2005; 139B:54-60.

34. Almasy L, Blangero J. Multipoint quantitative-trait linkage analysis in general pedigrees. Am J Hum Genet 1998;62:1198-1211.

35. Green RL. Introduction. In: Green RL, Editor. The MMPI: Use with Specific Populations. Philadelphia, PA: Grune and Stratton, 1988, p.1-21.

36. Matsui M, Sumiyoshi T, Niu L, Kurokawa K, Kurachi M. Minnesota Multiphasic Personality Inventory profile characteristics of schizotypal personality disorder. Psychiatry Clin Neurosci 2002;56:442-452.

37. Walters GD. Schizophreia. In: Green RL, Editor. The MMPI: Use with Specific Populations. Philadelphia, PA: Grune and Stratton, 1988, p.50-73.

38. Moldin SO, Gottesman II, Erlenmeyer-Kimiling L. Psychometric validation of psychiatric diagnosis in the New York high-risk study. Psychiatry Res 1987;22:159-177.

39. Graham JR, Smith RL, Schwartz GF. Stability of MMPI configurations for psychiatric inpatients. J Consult Clin Psychol 1986;54:375-380.

40. Meehl PE. Schizotaxia, schizotypy, and schizophrenia. Am Psychol 1962; 17:827-838.

41. Gilberstadt H, Duker J. A Handbook of Clinical and Actuarial MMPI Interpretation. Philadelphia: W.B. Saunders Company; 1965.

42. Koh SD, Kayton L, Berry R. Mnemonic organization in young nonpsychotic schizophrenics. J Abnorm Psychol 1973;81:299-310.

43. Marks PA, Seeman W, Haller DH. The Actuarial Use of the MMPI With Adolescents and Adults. Baltimore: The Williams \& Wilkins Company; 1974.

44. Golden RR, Meehl PE. Detection of the schizoid taxon with MMPI indicators. J Abnorm Psychol 1979;88:217-233.

45. Fine HK. Studying schizophrenia outside the psychiatric setting. J Youth Adolesc 1973;2:291-301.

46. Steronko RJ, Woods DJ. Impairment in early stages of visual information processing in nonpsychotic schizotypic individuals. J Abnorm 
Psychol 1978;87:481-490.

47. Koh SD, Peterson RA. Perceptual memory for numerousness in "nonpsychotic schizophrenics." J Abnorm Psychol 1974;83:215-226.

48. Schulman SM. Cognitive deficit in students identified by the elevated 2-7-8 code of the MMPI. Diss Abstr Int 1976;37:3096B.

49. Dahlstrom WG, Welsh GS, Dahlstrom LE. An MMPI Handbook: Vol. II. Research Applications. Minneapolis: University of Minnesota Press; 1975.

50. Sim M, Kim JH, Yim SJ, Cho SJ, Kim SJ. Increase in harm avoidance by genetic loading of schizophrenia. Compr Psychiatry 2012;53:372-378. 51. Smith MJ, Cloninger CR, Harms MP, Csernansky JG. Temperament and character as schizophrenia-related endophenotypes in non-psychotic siblings. Schizophr Res 2008;104:198-205.

52. Yoneyama E, Matsui M, Kawasaki Y, Nohara S, Takahashi T, Hagino H, et al. Gray matter features of schizotypal disorder patients exhibiting the schizophrenia-related code types of the Minnesota Multiphasic Personality Inventory. Acta Psychiatr Scand 2003;108:333-340. 